\title{
Mapping Photography
}

\author{
Sam Bark \\ EsriUK, Sam Bark-sbark@esriuk.com
}

Keywords: Cartography, Photography, Web Mapping, Storymaps, Esri

\begin{abstract}
:
As a fresh face to the cartography world, I am always inspired by experienced cartographers and the wonderful maps they've designed. The consideration of colours, the layout design and composition applied to create the perfect mapping product. Using their webinars, tutorials and wise words, I always try to create my own perfect cartographic map but with my own unique style applied.

With a fascination for photography, this helps me in more ways than just decorating my front room, often acting as a source of inspiration when designing maps. My cartography brain automatically merges the two passions, focusing on the photographs colours, layout and composition, before transferring that style to my map.

Within this presentation, I want to explore the world of mapping and photography. How can photographs shape the way our maps look? With a specific focus on internet mapping, I want to showcase how we can create maps inspired from photography, whether that's your iPhone 6 or a $£ 4000$ camera.

For my presentation, I will customise basemaps using a vector basemap editor and walk through this extremely useful tool. I'll then also focus on how to share your stories in an engaging and easy-to-use platform of Esri's Storymaps. The session will hopefully provide a unique style to designing your maps, that requires nothing but a camera phone and maybe a pretty landscape.
\end{abstract}

